\title{
Opinion \\ The value of scientific patience
}

\author{
IOANNIS N. MAMMAS ${ }^{1-3}$ and DEMETRIOS A. SPANDIDOS ${ }^{1}$
}

\author{
${ }^{1}$ Laboratory of Clinical Virology, School of Medicine, University of Crete, 71003 Heraklion; ${ }^{2}$ First Department of Paediatrics, \\ University of Athens School of Medicine, 11527 Athens; ${ }^{3}$ Paediatric Clinic, Aliveri, 34500 Island of Euboea, Greece
}

Received July 22, 2019; Accepted August 26, 2019

DOI: $10.3892 / \mathrm{etm} .2019 .7952$

'Face inequity with patience'

Aristotle

In the first supplement special edition on Paediatric Virology of the Experimental and Therapeutic Medicine, two of the world's most significant scientists in the modern history of Medicine met one another in a really unique way. The first scientist was Nobelist Laureate Professor Harald zur Hausen, Professor Emeritus of Virology at the Deutsches Krebsforschungszentrum in Heidelberg in Germany, known as 'the father of human papillomaviruses (HPV) Virology', who was awarded the Nobel Prize in 2008 for his discovery of HPV causing cervical cancer. Interestingly, in the context of the '3rd workshop on Paediatric Virology', held in Athens on October 7th, 2017, he admitted in his pre-congress interview that 'George Papanicolaou should definitely have received the Nobel Prize' (1). The second scientist was a doctor from the island of Euboea, Greece, known as the 'father of Exfolliative Cytology', Dr George N. Papanicolaou, whose student, Dr Neda Voutsa-Perdiki, in the context of the same event in Athens, gave a very touching interview, published in the same issue of the Experimental and Therapeutic Medicine, where she stated that: 'Papanicolaou would have been very impressed by Professor's Harald zur Hausen discovery' (2). Through this supplement special edition of the Experimental and Therapeutic Medicine, Professor Harald zur Hausen and Dr George N. Papanicolaou met one another and expressed their mutual scientific admiration. Both scientists studied the human cervix and their contributions to the scientific community were more than significant. Dr Papanicolaou's smear test has already saved millions of women from cervical cancer's mortality. Professor zur Hausen's discovery led to the development of the vaccines against HPV, as well as their implementation into the

Correspondence to: Professor Demetrios A. Spandidos, Laboratory of Clinical Virology, School of Medicine, University of Crete, 71003 Heraklion, Greece

E-mail: spandidos@spandidos.gr

Key words: Harald zur Hausen, George N. Papanicolaou, Paediatric Virology, medical education, patience clinical practice among female adolescents, aiming to eradicate HPV infections and HPV-associated mortality.

Most importantly, both scientists had to wait for several years before their ideas and results would be accepted by the worldwide scientific community. In January, 1928, Dr Papanicolaou first announced his findings at the Third Race Betterment Conference in Battle Creek, Michigan, but these were met with scepticism and resistance from the scientific community (2). This rejection did not deter Dr Papanicolaou from continuing his research in this field in 1939, until eventually his findings were published on March 11, 1941. At this time, the Pap smear test technique won acceptance and soon became widely undertaken as a routine screening methodology, worldwide. Similarly, in the early 1970's Professor zur Hausen's findings were managed with scepticism, at a time when the false dogma implicating herpes simplex viruses in the aetiology of cervical cancer had gained a catholic scientific acceptance (1). His principal observation was that HPV was not a single virus, but rather a group of many with a major heterogeneity. In the late 1970s, this finding led his research team to be the first to isolate HPV 6 and HPV 11 from genital wart biopsies, and HPV 16 and HPV 18 from cervical cancer biopsies, and to hypothesise that the cause of cervical cancer is mainly associated to specific types of HPV. This hypothesis achieved a major breakthrough in the field of Virology and led to tremendous progress being made in women's health in the coming years. Nevertheless, the scientific community was initially negative to accept that cervical cancer is caused by HPV. Both scientists had to wait with patience for several years for their work to be acknowledged; however, their patience led to the final recognition of their work.

According to Aristotle (3), the greatest philosopher and scientist of the ancient Greek world, patience is indeed one of the most important human virtues. In his book entitled 'Ritoriki A', he asks humans to 'face inequity with patience'

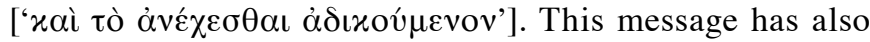
been highlighted by several modern philosophers and writers, from Leo Tolstoy in War and Peace, where 'the strongest of all warriors are these two: time and patience' (4) to Paulo Coelho in Veronika Decides to Die, where 'the two hardest tests on the spiritual road are the patience to wait for the right moment and the courage not to be disappointed with what we encounter' (5). The examples of Professor Harald zur Hausen 
and Dr George N. Papanicolaou prove that patience is not only a virtue in a moral and political sense, but also in scientific terms; a virtue, which is an essential principle that should definitely be taught in modern medical schools.

\section{Acknowledgements}

This article is published in the third supplement issue of the Experimental and Therapeutic Medicine, which is dedicated to Paediatric Virology. This edition is performed in the context of the '5th workshop on Paediatric Virology' (Sparta, Greece, October 12, 2019) organized by the Paediatric Virology Study Group (PVSG) and supported by the Department of Clinical Virology of the University of Crete School of Medicine and the First Department of Paediatrics of the University of Athens School of Medicine. We would like to thank all the members of the PVSG for their valuable comments and corrections. We would also like to thank Dr Melpomeni P. Kountouri (Geneva, Switzerland), Dr Anastasia Stouraiti (London, United Kingdom) and Mr. George D. Karapas (Adelaide, Australia) for reviewing this article.

\section{References}

1. Mammas IN and Spandidos DA: Paediatric Virology as new educational initiative: An interview with the Nobelist Professor of Virology, Harald zur Hausen. Exp Ther Med 14: 3329-3331, 2017.

2. Mammas IN and Spandidos DA: George N. Papanicolaou (1883-1962), an exceptional human, scientist and academic teacher: An interview with Dr Neda Voutsa-Perdiki. Exp Ther Med 14: 3346-3349, 2017

3. Aristotle: Ritoriki 1. Kaktos Editions, 1995

4. Tolstoy L: War and Peace. Oxford University Press, 1998.

5. Coelho P: Veronika Decides to Die. Translated from the Portuguese by Margaret Jull Costa. HarperCollins, 2000.

This work is licensed under a Creative Commons Attribution-NonCommercial-NoDerivatives 4.0 International (CC BY-NC-ND 4.0) License. 